\title{
Forecasting of Rice Production using the Meteorological Factor in Major States in India and its Role in Food Security
}

\author{
P. Mishra ${ }^{1}$, P.K. Sahu ${ }^{2}$, Monika Devi $^{3}$, Chellai Fatih $^{4}$ and A.J. Williams ${ }^{5}$ \\ ${ }^{1}$ College of Agriculture, JNKVV, Powarkheda, Hoshangabad, Madhya Pradesh, India \\ ${ }^{2}$ Department of Agricultural Statistics, Bidhan Chandra Krishi Viswavidyalaya, Mohanpur, Nadia West Bengal, India \\ ${ }^{3}$ Department of Mathematics \& Statistics, CCSHAU, Hisar, Haryana, India \\ ${ }^{4}$ Department of Based Education, University of Ferhat Abbas, Algeria \\ ${ }^{5}$ BTC College of Agriculture and Research Station, IGKV, Bilaspur, Chhattisgarh, India
}

*Corresponding author: pradeepjnkvv@gmail.com (ORCID ID: 0000-0003-4430-886X)

Paper No. 881

Received: 11-01-2021

Revised: 27-02-2021

Accepted: 13-03-2021

\begin{abstract}
The world as well as in India, rice is playing a major role in food security. Production factors (like rainfall, minimum temperature, fertilizer consumption, an area under irrigation for a particular crop) are very crucial for crop productivity. Forecasting is always important for policy implication and planning purposes of the country. In the present investigation, the projection has been made using simple ARIMA and ARIMAX (with the inclusion of crop inputs in ARIMA models). In terms of less error in model and projection, wise ARIMAX model was found better compared to simple ARIMA. In this present study, forecasting has been attempted with the inclusion of meteorological factors using ARIMA modeling up to the year 2022. This study reveals the future trend of rice production as well as a factor affecting productivity. Among the major states, West Bengal would lead the state in India in rice production, with a productivity of $4758 \mathrm{~kg} / \mathrm{ha}$, while Punjab will be the leader in productivity in the year 2022. This prediction would be helpful for policy implication and food security of the country.

\section{Highlights}

(0 By and large, there has been an expansion in the area, production, and yield of rice in major growing states, including the whole of India. In the majority of the states, including the whole of India, the average rainfall has increased during the study period.

( In rice area, production, and productivity data, none of the series is stationary; Ist differencing with original data makes all the series stationary.

0 Inclusions of different factors of productions in the best fitted time series model increase the accuracy and forecasting power compared to the simple ARIMA model.
\end{abstract}

Keywords: Modelling, forecasting, rainfall, temperature, food security, ARIMAX

World population, in general, and the population of developing countries, in particular, has experienced a sharp increase in recent decades. Provide food to these increasing human populations tough task to the planners of the individual countries and also the world bodies. The vast majority of rice producers are in Asia, which is the emblematic cereal. There are 200 million rice farms on our planet, and $50 \%$ of the world's population depends on it for work or consumption. Agriculture in India is an important economic sector of India and one of the most important agricultural productions on the planet. The sector employs almost two-thirds of the workforce (49\% of jobs in 2012), out of a total population of 1.1 billion, of which $72 \%$ are rural.

How to cite this article: Mishra, P., Sahu, P.K., Devi, M., Fatih, C. and Williams, A.J. 2021. Forecasting of Rice Production using the Meteorological Factor in Major States in India and its Role in Food Security. IJAEB, 14(1): 51-62.

Source of Support: None; Conflict of Interest: None 
Agriculture contributes approximately 17-18 percent to the country's GDP. Rice belongs to a family of starchy foods that provide vegetable protein and contain complex carbohydrates. These are gradually released into the body and provide energy as and when needed (Ramesh 2020). Nutritionists recommend increasing carbohydrate intake to contribute more than $50 \%$ of daily energy intake. An increase in the consumption of starchy foods (complex carbohydrates) is therefore recommended. (Khush 2003). Crop yield is influenced by several meteorological factors. Weather factors play a vital role in production of crops, and if weather factors (viz. rainfall, maximum temperature, minimum temperature, etc.) are not favorable to the crop, then the crop cannot be grown well. The best climatic conditions for growing rice are heat and heavy rainfall (monsoon: rain for several days); any modification of these two factors could affect the productivity of these crops (Kaul 2006 \& Raiger et al. 2019). Therefore, studying and analyzing the effects of associated metrological factors is also necessary for effective crop prediction. To identify important factors affecting crop diversification, and by using time series data, multiple regression analysis was performed (Kebebe 2000; Joshi et al. 2004; 2006). Mishra et al. (2015) forecasted the wheat as well as total food grain production using meteorological factors likes (Rainfall \& temperature). Biswas et al. (2018) studied the impact of temperature on rice yield on kharif season. With this backdrop, the present study attempts to examine the trend of factors of production on rice in major growing states of India, modeling, and projecting of rice production in these states along with the whole of India taking in to account the weather factors which are important in the production process. The present investigation has following Aims.

To see the nature of methodological factors (Like, Rainfall, Minimum temperature, maximum temperature) and other factors of production (like Fertilizer use, Irrigation area, and pesticide consumption).

To compare the model between ARIMA (Without factors) and ARIMAX (With factors) used for forecasting.

To show the effect of factors (like Rainfall, temperature, Irrigation, Fertilizer consumption) in productivity and use in projection.

\section{MATERIALS AND METHODS}

\section{Selection of study area}

The following three states: West Bengal, Uttar Pradesh, and Punjab, are contributing around 37\% of total production in India from 33\% area under rice in India during 2017-18. In order to select the major growing states in India for rice, production, percentage share of each and every state are examined. The information is presented in table 1.

Table 1: Contribution of different states towards rice production ('000 tons) in India (2017)

\begin{tabular}{|c|c|c|}
\hline State & Rice & $\%$ to India \\
\hline Andhra Pradesh & 8051.30 & 7.25 \\
\hline Assam & 5158.00 & 4.65 \\
\hline Bihar & 7296.40 & 6.57 \\
\hline Chhattisgarh & 6910.60 & 6.23 \\
\hline Gujarat & 1762.00 & 1.59 \\
\hline Haryana & 3946.80 & 3.56 \\
\hline Himachal Pradesh & 130.50 & 0.12 \\
\hline Jammu and Kashmir & 596.30 & 0.54 \\
\hline Jharkhand & 3775.20 & 3.40 \\
\hline Karnataka & 2359.00 & 2.13 \\
\hline Kerala & 418.70 & 0.38 \\
\hline Madhya Pradesh & 3908.40 & 3.52 \\
\hline Maharashtra & 2660.50 & 2.40 \\
\hline Odisha & 7619.00 & 6.86 \\
\hline Punjab & 12283.30 & 11.07 \\
\hline Rajasthan & 428.80 & 0.39 \\
\hline Tamil Nadu & 6395.90 & 5.76 \\
\hline Telangana & 5825.00 & 5.25 \\
\hline Uttar Pradesh & 13345.90 & 12.02 \\
\hline Uttarakhand & 663.00 & 0.60 \\
\hline West Bengal & 14990.00 & 13.50 \\
\hline Others & 2483.00 & 2.24 \\
\hline All India & 111007.80 & 100.00 \\
\hline
\end{tabular}

Source: Ministry of Agriculture and Cooperation, Govt. of India.

Thus, these three states have got tremendous importance in all India's production of rice vis-à-vis food and dietary security of the nation. As such, this study has taken these three states along with that of the whole of India. The data have been obtained for the area, production, productivity of rice, as well as a factor effecting of rice production like weather factors, fertilizer, and pesticide use from different sources for the period as provided below. 


\begin{tabular}{ll}
\hline Information on & Period \\
\hline Area, Production and yield of rice & $1950-2009$ \\
Average rainfall (mm) & $1961-2009$ \\
Average maximum temperature & $1961-2009$ \\
Average minimum temperature & $1961-2009$ \\
Crops wise irrigation & $1965-2009$ \\
Fertilizer consumption & $1975-2009$ \\
Pesticide consumption & $1989-2009$ \\
\hline
\end{tabular}

\section{Source of data}

The information on production, yield of rice, area in the above major states and India for the period 1950-2010 was collected from www.indiastat. com and Agriculture Statistics at a glance. The information on pesticide consumption could be collated for the period from 1989 to 2010 and that of fertilizer consumption from 1975-2010 from the book of fertilizer statistics 1978-2005. Meteorological data could be obtained for 1961-2010 from the website www.indiawaterportal.com. Weather data is compiled into year data with the help of monthly data. Information on irrigation for different crops or different states were collated from different issues of "Agriculture at glance" Anonymous. (2017).

Summary Statistics: Study of historical or timeseries data is a challenging task to a researcher in terms of data handling and data analysis. Present investigation summary statistics have been worked out for factors of production. Generally, analytical tool starts with description and summarization of the information collected in any study. As such, this study also describe the characteristics of each series via the central tendency (average arithmetic, percentages ...) and the measurements of dispersion (standard deviation, variance, ....).

As one of the objectives of the present study is to forecast the parameters using ARIMA models and it is advised to have at least thirty data points for effective and successful modeling, the study prefers not to consider pesticide consumption data (having data point for 21 years only) for the purpose excepting for descriptive study.

\section{Grubb's Test for detecting outliers}

Time series data, in economic, financial fields are characterized by the presence of outlier. An outlier in this context is an observation, somewhat different from the rest of the observations in the series. There are several ways to detect outliers. Grubbs' test is one of such tests particularly suitable under a large set of data points, Grubb (1950, 1969, 1972). To use this test, we have to estimate the mean of observation $\underline{X}$, the standard error of the data set, and a distance $D$, between the value, suspected $x_{i}$ of being an outlier and the mean value, $\quad \underline{|x \quad \underline{X}|}$ then, we compare it with a distance limit $D_{l i m^{\prime}}$ so, we reject the hypothesis of no outliers if,

$$
D>D_{\lim }=\frac{N-1}{\sqrt{N}} \sqrt{\frac{\left(t_{\frac{\alpha}{2 N}, N-2}\right)^{2}}{N-2\left(t_{\frac{\alpha}{2 N}, N-2}\right)^{2}}}
$$

With, ${ }^{t}\left(\frac{\alpha}{2 N}, N-2\right)$ the critical value of the student distribution.

\section{Test of Randomness}

Test of randomness is an initial step to know the behaviour of any time series data as to whether the observations are following any pattern or changing randomly. This is to test:

$$
\begin{aligned}
& \left\{H_{0}: X_{t}\right. \text { are random.variable.iid } \\
& \left.H_{1}: X_{t} \text { are not random.variable.iid }\right\}
\end{aligned}
$$

A time series $X_{t}$ has a turning point at time $t$ if one of the following two situations is true:

$$
\begin{aligned}
& X_{t}>X_{t-1} \text { and } X_{t}>X_{t+1} \\
& \text { Or } X_{t}<X_{t-1} \text { and } X_{t}<X_{t+1}
\end{aligned}
$$

Let $H$ be the number of turning points of a time series of size $n$. Under $H_{0^{\prime}} H \leadsto N\left(\mu_{H}, \sigma_{H}^{2}\right)$ with:

$$
\mu_{H}=\frac{2(n-2)}{3}, \sigma_{H}^{2}=\frac{16(n-9)}{90}
$$

If $\frac{\left|H-\mu_{H}\right|}{\sigma_{H}}<Z_{1-\frac{\alpha}{2}}$ we accept the null hypothesis; where $Z_{1-\frac{\alpha}{2}}$ is the quintile of order $\left(1-\frac{\alpha}{2}\right)$ of the standard normal distribution (Gouri 1984). 
In reality, this test is used to test the lack of autocorrelation, and it is a non-parametric test. The parametric tests best known in the literature are those of Box and Pierce (1970) and Ljung and Box (1978).

\section{Box-Jenkins models}

The Box-Jenkins (1976) method is based on the principle of parsimony for building linear timeseries models. Intriligator et al. (1996). Under this principle, in model construction, we employ the minimal possible number of parameters that mimics the properties of the sample. It is a methodology for the systematic study of time series from their characteristics in order to determine, in the family of ARMA models, the most suitable to represent the studied phenomenon. Technically, the Box-Jenkins method is an iterative cycle: Model Identification $\leftrightarrows$ Model Estimation $\leftrightarrows$ Model Validation $\Rightarrow$ Forcasting.

The identification phase is the most important and the most difficult: it consists in determining the appropriate model in the family of $A R M A$ models. It is based on the study of simple and partial correlograms. At the estimation stage, different methods can be used: (Least Squares Method, Yule-Walker Equations, Maximum of Likelihood Estimation...). Then validation (diagnostic checks) is applied to establish if the chosen model adequately represents the given data set. If the model is well validated, we past to the forecasting process. If any inadequacy is found, we return to the identification phase until the best representation is found.

\section{Autoregressive model}

In an autoregressive process, $A R(p)$ of order, $p$ the present observation $X_{t}$ is generated by a weighted average of past observations until the $p^{\text {th }}$ period, $A R(p)$ is written as follow:

$$
X_{t}=c+\sum_{i=1}^{p} \theta_{i} X_{t-i}+\varepsilon_{t}, \theta_{i} \in R, \varepsilon_{t} \sim N\left(0, \delta_{\varepsilon}\right) .
$$

Where $\theta_{1}, \theta_{2}, \ldots \theta_{p}$ model of the parameter to be estimated, $c$ is a stable and $\varepsilon_{t}$ : is i.i.d with mean zero. The constant $c$ does not change the stochastic properties of the process; generally we normalize it to be $c=1$.

\section{Moving Average model: (sub-section)}

The moving average process, with notation $M A(q)$ refers to series of order $q$, which suppose that an observation $X_{t}$ is generated by a weighted average of noise $\varepsilon_{t}$ until the $q^{\text {th }}$ period, we represent it by:

- $M A(1): X_{t}=\varepsilon_{t}-\alpha_{1} \varepsilon_{t-1}$.

- $M A(2): X_{t}=\varepsilon_{t}-\alpha_{1} \varepsilon_{t-1}-\alpha_{2} \varepsilon_{t-2}$ with: $E\left(\varepsilon_{t}\right)=\sigma_{\varepsilon}^{2}$

- ...

- $M A(q): X_{t}=\varepsilon_{t}-\alpha_{1} \varepsilon_{t-1}-\alpha_{2} \varepsilon_{t-2}-\ldots-\alpha_{q} \varepsilon_{t-q}$

As a general presentation of such process, we reformulate it as:

$$
X_{t}=\mu+\sum_{i=1}^{q} \alpha_{i} \epsilon_{t-1}
$$

Where $\alpha_{1}, \alpha_{2}, \ldots, \alpha_{q}$ the are the parameters of the process $(q), \mu$ is the expectation of $X_{t^{\prime}}$ and the $\epsilon_{t^{\prime}}$ $\epsilon_{t-1}, \epsilon_{t-2}, \ldots, \epsilon_{t-q}$ error terms. $\epsilon_{0}$ is often normalized to be equal to 1 .

\section{Autoregressive Moving Average Process (ARMA)}

We can combine the two previous models $A R(p)$, $M A(q)$, to obtain a mixed autoregressive moving average model of order $p$ and $q, A R M A(p, q)$ :

$$
\begin{aligned}
& (L) X_{t}=\alpha(L) \epsilon_{t} \\
& (L)=\theta_{0}+\theta_{1} L+\ldots+\theta_{p} L^{p} \\
& (L)=\alpha_{0}+\alpha_{1} L+\ldots+\alpha_{q} L^{q}
\end{aligned}
$$

Where: $\theta_{0}=\alpha_{0}=1$, and $v\left(\epsilon_{t}\right)=\sigma_{\varepsilon}^{2}$ and $E\left(\epsilon_{S} \in_{t}\right)=0, t \neq S$. So, ARMA an model represents a process generated by a grouping of the historical values of $X_{t}$ and the past errors $\epsilon_{t^{\prime}}$ (or disturbances). The models: $A R(p)$, $M A(q), A R M A(p, q)$, are representative only of time series that are: stationary in tendency; seasonally adjusted (Mishra et al. 2021 \& 2020).

\section{ARIMAX Model or Transfer Function Model}

In practice, we fit a relationship between a dependent variable $X_{t}$ (or output) and an independent variable $Z_{t^{\prime}}$ (or input); also, when estimating such relationship, in reality, the impact of change in $Z_{t}$ may not appear (realized) instantly, but takes time (e.g., effect on climate changes on agriculture production), this impact is called a dynamic response, and the model that takes into account this dynamic 
effect is called a transfer function model. Intriligator et al. (1996). We can formulate this relationship as:

$$
X_{t}=\gamma_{0} Z_{t}+\gamma_{1} Z_{t-1}+\gamma_{2} Z_{t-2}+\ldots=\gamma(L) Z_{t}
$$

Generally, $\gamma(L)=\frac{\beta(L)}{\varphi(L)}$ we put:, this transformation allows the dynamic relation between $X_{t}$ and $Z_{t}$ to be represented as:

$$
\varphi(L) X_{t}=\beta(L) Z_{t}
$$

We add $\epsilon_{t}$ a noise to the relationship (which is affected by noise, omitted variables...) between $Z_{t}$ and $X_{t}$ :

$$
X_{t}=\gamma(L) Z_{t}+\mu_{t}
$$

We assumed $\epsilon_{t}$ follow an $A R M A(p, q)$ process:

$$
\theta_{t}=\frac{\alpha(L)}{\theta(L)} \epsilon_{t}
$$

The final model of ARIMAX is a combination of: a system part and an ARMA noise model,

$$
X_{t}=\frac{\beta(L)}{\varphi(L)} Z_{t}+\frac{\alpha(L)}{\theta(L)} \epsilon_{t} .
$$

The difference between a transfer function model and an ARIMA model is that in the former case, the input variables (exogenous) $Z_{t}$ is observable, while in the latter case, the innovation (or error) $\epsilon_{t}$ is not observable. The main interest (advantage) of ARIMAX model is to use it to forecast output variable $X_{t}$ from future values of the input variables $Z_{t}$.

\section{Checking for model adequacy}

Among the competitive Box- Jenkins model best model is selected on the basis of maximum $R^{2}$, minimum root mean square error (RMSE), minimum mean absolute percentage error (MAPE), minimum of maximum average percentage error (MaxAPE), minimum of maximum absolute error (MaxAE), minimum of Normalized BIC. Any model which has fulfilled most of the above criteria is selected. This part of the study provides some goodness-of-fit tests and measures used in econometric modeling.
Coefficient of determination $\boldsymbol{R}^{2}$ : is the proportion of the total of the dependent variable $Y_{t}$ that is explained by the regression; it has different expressions:

$$
R^{2}=\frac{\sum_{t}\left(\hat{Y}_{t}-\underline{Y}\right)^{2}}{\sum_{t}\left(Y_{t}-\underline{Y}\right)^{2}}=1-\frac{\sum_{t} e_{t}^{2}}{\sum_{t}\left(Y_{t}-\underline{Y}\right)^{2}}
$$

There is an inverse relationship between the sum of squared errors $\Sigma_{t}$ and $e_{t}^{2}$ the value of $R^{2}$, under some conditions $R^{2}$, provide us is an estimation of the explanatory power of the estimated model.

Root Mean Squared Error, (RMSE): is a measure characterizing the "precision" of the estimated model.

The best model is simply the one with the smallest value of RMSE.

$$
R M S E=\sqrt{\frac{\sum_{t}\left(Y_{t}-\hat{Y}_{t}\right)^{2}}{n}}=\sqrt{\frac{\sum_{t} e_{t}^{2}}{n}}
$$

Mean Absolute Percentage Error, (MAPE): also called: mean absolute percentage deviation (MAPD), allows us to measure the accuracy of a statistical forecasting method. The accuracy under this measure is expressed as a percentage:

$$
M A P E=\frac{100 \%}{n} \sum_{i=1}^{n}\left|\frac{Y_{i}-\hat{Y}_{i}}{Y_{i}}\right|
$$

Mean absolute error, (MAE). In time series analysis, mean absolute error (MAE) is a measure of forecast error, which is the difference the observed data set $Y_{i}$ and the regression part $\hat{Y}_{i}$ :

$$
M A E=\frac{\sum_{i=1}^{n}\left|Y_{i}-\hat{Y}_{i}\right|}{n}=\frac{\sum_{i=1}^{n}\left|e_{i}\right|}{n}
$$

Maximum Absolute Percentage Error. (MaxAPE). Is a measure of the extreme forecasted errors. These statistics give us an idea about the outlier among the forecasted errors: $\hat{e}_{i}: i: 1,2, \ldots n$.

$$
\operatorname{Max} A P E=100 \% \cdot \operatorname{Max}\left(\left|\frac{Y_{i}-\hat{Y}_{i}}{Y_{i}}\right|\right) .
$$

Maximum Absolute Error, (MaxAE). At contrast of, maximum absolute error, is expressed in the 
same unit of measure as the data set $Y_{\text {, }}$ the MaxAE, estimate (determine) the maximum of the forecasted errors:

$$
\operatorname{Max} A E=\operatorname{Max}\left(\left|Y_{i}-\hat{Y}_{i}\right|\right)=\operatorname{Max}\left|e_{i}\right| .
$$

Normalized Bayesian Information Criterion: Model selection is a well-known problem in statistics, and information theory provides a rigorous framework for the development of efficient estimators. Among the answers to this problem: is the minimization of a penalized criterion. The first criteria that appear in the literature are Akaike Information Criterion (AIC, Akaike (1973), Bayesian Information Criterion (BIC, Schwaz (1978).

$$
B I C=-2 \ln \ln (L)+k \cdot \ln \ln (N) .
$$

To obtain the normalized $B I C$, we just divide the BIC by $2 N$,

$$
N B I C=-\frac{1}{N} \ln \ln (L)+\frac{k}{2 N} \cdot \ln \ln (N) .
$$

For $N$ large, the second term converges to zero. The model that will be selected is the one that minimizes the BIC criterion.

\section{RESULTS AND DISCUSSION}

Weather factors have a very crucial role in rice plant growth. So, descriptive statistics tell the story of these factors of production. From table 1, one can see the pattern of climatologically factors (rainfall, maximum and minimum temperature) and factors affecting the production. The average annual rainfall in West Bengal is estimated at 1523 mm, with the highest being at $2329 \mathrm{~mm}$, while the minimum annual rainfall is $961 \mathrm{~mm}$. There has been a tendency of increased rainfall over the years as depicted by the simple growth rate of $16 \%$ during 1961 -2009. But in comparison to the growth rate of whole India (38\%) it is far below. The positive skewness and kurtosis values reveal that during the initial period under study, the change has taken place. The mean annual rainfall of Uttar Pradesh is $894 \mathrm{~mm}$, with maximum annual rainfall (1260 mm) received during 1980 that is almost $25 \%$ higher than the mean. While the annual minimum rainfall of $534 \mathrm{~mm}$ was recorded during 2001. The state has achieved a simple growth rate of $371 \%$ during the period. The $\beta_{1}$ value (-0.2) of coefficient of skewness suggests maximum asymmetry of data during the later part of the period under investigation. The value of $\beta_{2}$ coefficient of kurtosis is near about (- 0.8$)$ during the study. Similarly, in Punjab, the annual rainfall has varied by three folds, from a mere 290 $\mathrm{mm}$ to $785 \mathrm{~mm}$ during the period under study. During the period under study, an overall growth rate of more than $38 \%$ in average annual rainfall for the whole of India is recorded.

The average maximum temperature of West Bengal was highest at $32.7{ }^{\circ} \mathrm{C}$ and the lowest at $29.4{ }^{\circ} \mathrm{C}$, registering a change of almost $3.4 \%$. The $\beta_{1}$ value (0.8) of coefficient of skewness suggests the asymmetric nature of data during the study period under investigation. In Uttar Pradesh average maximum temperature $\left(32.9^{\circ} \mathrm{C}\right)$ is received during 1977 which was almost equal to the mean maximum temperature and registering virtually no growth during the period under consideration. In Punjab, the average maximum temperature is similar to the whole of India during the period under investigation. The highest average maximum temperature for the whole of India was $32.7^{\circ} \mathrm{C}$, and that of the lowest average maximum temperature was at $30.9^{\circ} \mathrm{C}$ with an average of $31.7^{\circ} \mathrm{C}$. In Punjab, the average minimum temperature varies between 16 to $18{ }^{\circ} \mathrm{C}$ during the period with an average of 17.1 ${ }^{\circ} \mathrm{C}$ and virtually registering no growth rate (only). The estimated average of the irrigated area under rice in West Bengal is $3011 \times 10^{3}$ hectare. The highest irrigated area under rice was $615 \times 10^{4}$ the hectare, while the lowest was at 1251 thousand hectares. West Bengal is the state which has a registered maximum growth rate (160\%). In Uttar Pradesh, the irrigated area under rice has the highest at $608 \times 10^{4}$ hectare in 1999 and lowest at $633 \times 10^{3}$ hectare in 1964; recording a growth rate of only $1.01 \%$. In Punjab, irrigation for rice recorded the highest rate in 2008 at $2734 \times 10^{3}$ hectare and the lowest rate in 1965 at $240 \times 10^{3}$ hectare. For the whole India, irrigation under rice has increased from $12146 \times 10^{3}$ hectare to $25465 \times 10^{3}$ hectare registering a growth of almost $100 \%$. Expansion in irrigation potential is most warranted in augmenting rice production, particularly under high input-intensive production regime.

The mean total fertilizer consumption of Uttar Pradesh is estimated at 2059 thousand tonnes. 
Table 1: Per se performance of climatological and some input factors of production of rice

\begin{tabular}{|c|c|c|c|c|c|c|c|c|c|c|c|c|}
\hline \multicolumn{7}{|c|}{ West Bengal } & \multicolumn{6}{|c|}{ Uttar Pradesh } \\
\hline & ARF & Tmax. & Tmin. & IA & TFC & PC & ARF & Tmax. & Tmin. & IA & TFC & PC \\
\hline Minimum & 961 & 29.5 & 19.4 & 1251.0 & 129.7 & 3000.0 & 534.3 & 31.3 & 17.9 & 633.0 & 223.1 & 1855.0 \\
\hline Maximum & 2329.526 & 32.8 & 21.3 & 6150.0 & 1519.3 & 4785.0 & 1260.8 & 33.0 & 19.7 & 6080.0 & 4032.8 & 9563.0 \\
\hline Mean & 1523.154 & 30.8 & 20.4 & 3011.6 & 783.8 & 3937.3 & 894.7 & 32.2 & 18.9 & 2951.0 & 2059.8 & 7533.9 \\
\hline S.E. & 38.728 & 0.1 & 0.1 & 312.9 & 74.0 & 109.9 & 26.7 & 0.1 & 0.1 & 325.3 & 183.5 & 356.9 \\
\hline Kurtosis & 0.772 & 6.9 & 0.4 & -1.6 & -1.4 & -0.5 & -0.8 & -0.8 & 0.6 & -1.6 & -0.8 & 8.4 \\
\hline SGR(\%) & 16.522 & 3.5 & -2.0 & 160.5 & 364.4 & 1.8 & 371.4 & 0.2 & 2.1 & 1.0 & 248.6 & 1.5 \\
\hline \multicolumn{7}{|c|}{ Punjab } & \multicolumn{6}{|c|}{ India } \\
\hline Minimum & 290.8 & 30.9 & 16.3 & 240.0 & 311.3 & 5610.0 & 848.9 & 30.9 & 16.3 & 12146.0 & 2080.0 & 35674.0 \\
\hline Maximum & 785.4 & 32.8 & 18.0 & 2734.0 & 2100.6 & 7400.0 & 1314.2 & 32.8 & 18.0 & 25465.0 & 24909.3 & 75033.0 \\
\hline Mean & 512.9 & 31.8 & 17.1 & 1574.4 & 1280.1 & 6694.6 & 1100.5 & 31.7 & 17.1 & 18062.9 & 11386.0 & 53436.5 \\
\hline
\end{tabular}

Annual rainfall (ARF) in mm, Average maximum and minimum temperature $\left(T_{\max }\right.$ and $T_{\text {min. }}$ ) in ${ }^{\circ} C$, Irrigated area(IA) in '000 ha, Total fertilizer consumption (TFC) in '000 tonnes, Pesticide consumption (PC) in MT (Metric tonnes).

Maximum (4032 thousand tonnes) fertilizer consumption (is recorded during 2008). Punjab is the state which has registered a minimum growth rate $(159 \%)$ in average total fertilizer consumption during the period. For whole India total fertilizer consumption has an average of 11386 thousand tones, with a minimum amount of 2080 thousand tones and maximum of 24909 thousand tones. Thus, from the study of fertilizer consumption, it is clear that there has been tremendous growth in the consumption of fertilizer during the period under study. Crop protection is one of the important aspects in augmenting food grain production, as such use of pesticides plays vital role in this aspect. West Bengal is the state which has registered a minimum growth rate $(1.7 \%)$ in average pesticide consumption during the period (1975-2009). In West Bengal average total pesticide consumption is estimated at 3937 MT with a standard error of 109 MT. In Uttar Pradesh pesticide consumption was highest at 9563 MT in 2008 and lowest at 1855 MT in 2003. Thus there is a great fluctuation in the use of pesticides. Similarly in Punjab maximum pesticide consumption was at 7400 MT during 1993 with a minimum of 5610MT. Whole India has doubled pesticide consumption; from mere $35674 \mathrm{MT}$ to 75033 MT during the period under study.

As discussed material and method section each any every series under the climatologically and input factors are subjected to test of outlier and randomness. Table (2) presents the results of the tests. The data further revealed that in some of series one can detect the outliers which were subsequently replaced by median of the respective series before further analysis. From the test of randomness one can see that annual rainfall in all the major states have changed randomly except for whole India. Thus, year to year regional changes in annual rainfall has made agriculture more and more dependent on assured irrigation. In, West Bengal the average maximum temperature has changed randomly. Also the average minimum temperatures, excluding whole India, in other major states are random in nature. Irrigated areas under rice, other major states including whole India have followed definite trends. This is definitely the indication of the clear cut policy and its implication with respect to the expansion of the irrigation potential of the country. Only in West Bengal total fertilizer consumption has changed randomly over the period. The results show the randomness nature of pesticide consumption in West Bengal, Punjab and whole India, in contrast to definite trends for pesticide consumption in Uttar Pradesh. From the above results it is quite clear that during the period under consideration, the rice production in major states, as well as in India have remained on the mercy of the weather parameters. 
Table 2: Test of outliers and randomness for climatological and some input factors of rice

\begin{tabular}{|c|c|c|c|c|c|c|c|c|c|c|c|c|}
\hline & ARF & Tmax. & Tmin. & IA & TFC & PC & ARF & Tmax. & Tmin. & IA & TFC & PC \\
\hline & \multicolumn{6}{|c|}{ West Bengal } & \multicolumn{6}{|c|}{ Uttar Pradesh } \\
\hline No. of observation & 50 & 50 & 50 & 44 & 34 & 20 & 50 & 50 & 50 & 44 & 34 & 20 \\
\hline No. of turning point ( $p$ ) & 29 & 27 & 33 & 12 & 18 & 9 & 31 & 26 & 28 & 18 & 13 & 8 \\
\hline $\mathrm{E}(\mathrm{P})$ & 32 & 32 & 32 & 28 & 21.3 & 12 & 32 & 32 & 32 & 28 & 21.3 & 12 \\
\hline $\mathrm{V}(\mathrm{P})$ & 8.5 & 8.5 & 8.5 & 7.5 & 5.7 & 3.2 & 8.5 & 8.5 & 8.5 & 7.5 & 5.7 & 3.2 \\
\hline${ }^{\tau} \mathrm{Cal}$ & -1.0 & -1.7 & 0.3 & -5.8 & -1.3 & -1.6 & -0.3 & -2.0 & -1.3 & -3.6 & -3.4 & -2.2 \\
\hline Inference & $\mathrm{R}$ & $\mathrm{R}$ & $\mathrm{R}$ & $\mathrm{T}$ & $\mathrm{R}$ & $\mathrm{R}$ & $\mathrm{R}$ & $\mathrm{T}$ & $\mathrm{R}$ & $\mathrm{T}$ & $\mathrm{T}$ & $\mathrm{T}$ \\
\hline \multirow[t]{2}{*}{ Outliers test } & No & Yes & No & No & No & No & No & No & No & No & No & Yes \\
\hline & \multicolumn{6}{|c|}{ Punjab } & \multicolumn{6}{|c|}{ India } \\
\hline No. of observation & 50 & 50 & 50 & 44 & 34 & 20 & 50 & 50 & 50 & 44 & 34 & 20 \\
\hline No. of turning point $(p)$ & 34 & 24 & 29 & 6 & 12 & 9 & 25 & 25 & 26 & 14 & 14 & 9 \\
\hline $\mathrm{E}(\mathrm{P})$ & 32 & 32 & 32 & 28 & 21.3 & 12 & 32 & 32 & 32 & 28 & 21.3 & 12 \\
\hline $\mathrm{V}(\mathrm{P})$ & 8.5 & 8.5 & 8.5 & 7.5 & 5.7 & 3.2 & 8.5 & 8.5 & 8.5 & 7.5 & 5.7 & 3.2 \\
\hline${ }^{\top} \mathrm{Cal}$ & 0.68 & -2.7 & -1.0 & -8.0 & -3.9 & -1.6 & -2.3 & -2.3 & -2.0 & -5.1 & -3.0 & -1.6 \\
\hline Inference & $\mathrm{R}$ & $\mathrm{T}$ & $\mathrm{R}$ & $\mathrm{T}$ & $\mathrm{T}$ & $\mathrm{R}$ & $\mathrm{T}$ & $\mathrm{T}$ & $\mathrm{T}$ & $\mathrm{T}$ & $\mathrm{T}$ & $\mathrm{R}$ \\
\hline Outliers test & No & No & No & No & No & No & No & No & No & No & No & No \\
\hline
\end{tabular}

Annual rainfall (ARF) in MM, Average maximum and minimum temperature $\left(T_{\max }\right.$ and $\left.T_{\text {min. }}\right)$ in ${ }^{\circ} \mathrm{C}$, Irrigated area(IA) in '000 ha, Total fertilizer consumption (TFC) in '000 tonnes, Pesticide consumption (PC) in MT (Metric tonnes), $R=$ Random, $T=$ Trend.

Table 3: Correlation of factors related with productivity of rice in major states of India

\begin{tabular}{lllll}
\hline \multirow{3}{*}{ Irrigated area } & West Bengal & Uttar Pradesh & Punjab & India \\
\cline { 2 - 5 } & 0.911 & 0.926 & 0.92 & 0.939 \\
Annual rainfall & $<.0001$ & $<.0001$ & $<.0001$ & $<.0001$ \\
& 0.213 & -0.296 & -0.115 & 0.329 \\
Tmax & 0.227 & 0.09 & 0.517 & 0.057 \\
& 0.417 & 0.476 & 0.252 & 0.262 \\
Tmin & 0.014 & 0.004 & 0.151 & 0.134 \\
\multirow{2}{*}{ Total fertilizer consumption } & 0.139 & 0.349 & 0.223 & 0.302 \\
& 0.433 & 0.043 & 0.205 & 0.082 \\
& 0.979 & 0.744 & 0.881 & 0.879 \\
\hline
\end{tabular}

Italicised letters indicate the significance levels of the corresponding correlation coefficients.

At the time of setting objective for present study, we assumed that the factors (rainfall, maximum and minimum temperature, net irrigated area of crop and total fertilizer consumption) are supposed to have a great role in productivity of rice. In this section attempts have been made to work out the degree of linear associationship and linear relationship among these parameters for rice crop. Correlation, analysis is taken up to find out the extent and actual linear relationship of productivity on these parameters. In all major rice producing states including whole India (table 3 ) it is found that rice yield is significantly and positively correlated with net irrigated area of rice and total fertilizer consumption. Thus, fertilizer use and irrigation are the two major contributing factors related to rice yield vis-a-vis rice production there was no significant effect of rainfall, average maximum and minimum temperature on rice productivity. This may be due to the fact that rice production in major producing states might have overcome the dependence on monsoon activities rather the irrigation potential and other than kharif rice is playing major role in total rice production.

Our next task is to forecast the observation for a short-run time. For the purpose we adopted the Box -Jenkins methodology as discussed in the material and method section. Data over the period 1975-2009 has been used for model estimation, and the data for years 2010 to 2017, are used to validate the estimated models. Best fitted models, as adjudged through model accuracy criteria discussed in material and method section, are used to forecast step for the years to 2022 . 
Economic data are characterized by instability over time, which produce what we call a no-stationary time series. Statistically, a stationarization of the series is necessary; by using: (i) the differencing operation, (in practice, the level of differencing $d=$ 2 is two) or (ii) transformation, especially in the case of series with a tendency (called a models). First order differencing was sufficient to make these stationary. It is found that from ARIMA $(0,1,1)$ model to ARIMA $(1,1,5)$ are the most appropriate models for modeling and forecasting the level of rice production. For increasing the accuracy and to outline the path of production, and the model building we incorporate different factors of productions in the selected models. The best model among ARIMAX is selected based on the minimum values of RMSE, MAE, MSE, MAPE, and maximum value of $\mathrm{R}^{2}$, NBIC (Mishra et al. 2015). From the model validation period data for the period 2010-2017, it is clear that ARIMAX models are comparatively better than the corresponding ARIMA models; hence the importance of inclusion of auxiliary variables in the model. With the inclusion of factors, on the basis of forecasted value in 2009-10 production of whole India is 96534 thousand tonnes almost similar findings were reported by Ravichandan et al. (2012) in rice in India. Thus, there would be an increase in production as well as productivity in major growing states. It is clearly visible that in the case of production of rice West Bengal would be the leading state of India during 2022-23; West Bengal is supposed to produce more than seventeen million tonnes of paddy from an estimated area of slightly above of six million hectare with a per hectare production of around 2.9 quintal. Though Uttar Pradesh will contribute maximum area under rice in India because of its lower productivity it will produce 13.7 million tones of rice from 6.71 million hectare of land at a yield rate of $2.47 \mathrm{q} / \mathrm{ha}$. Punjab is another major paddy producing state will continue

Table 4: ARIMA models for area, production and yield of rice in India including with factors and without factors

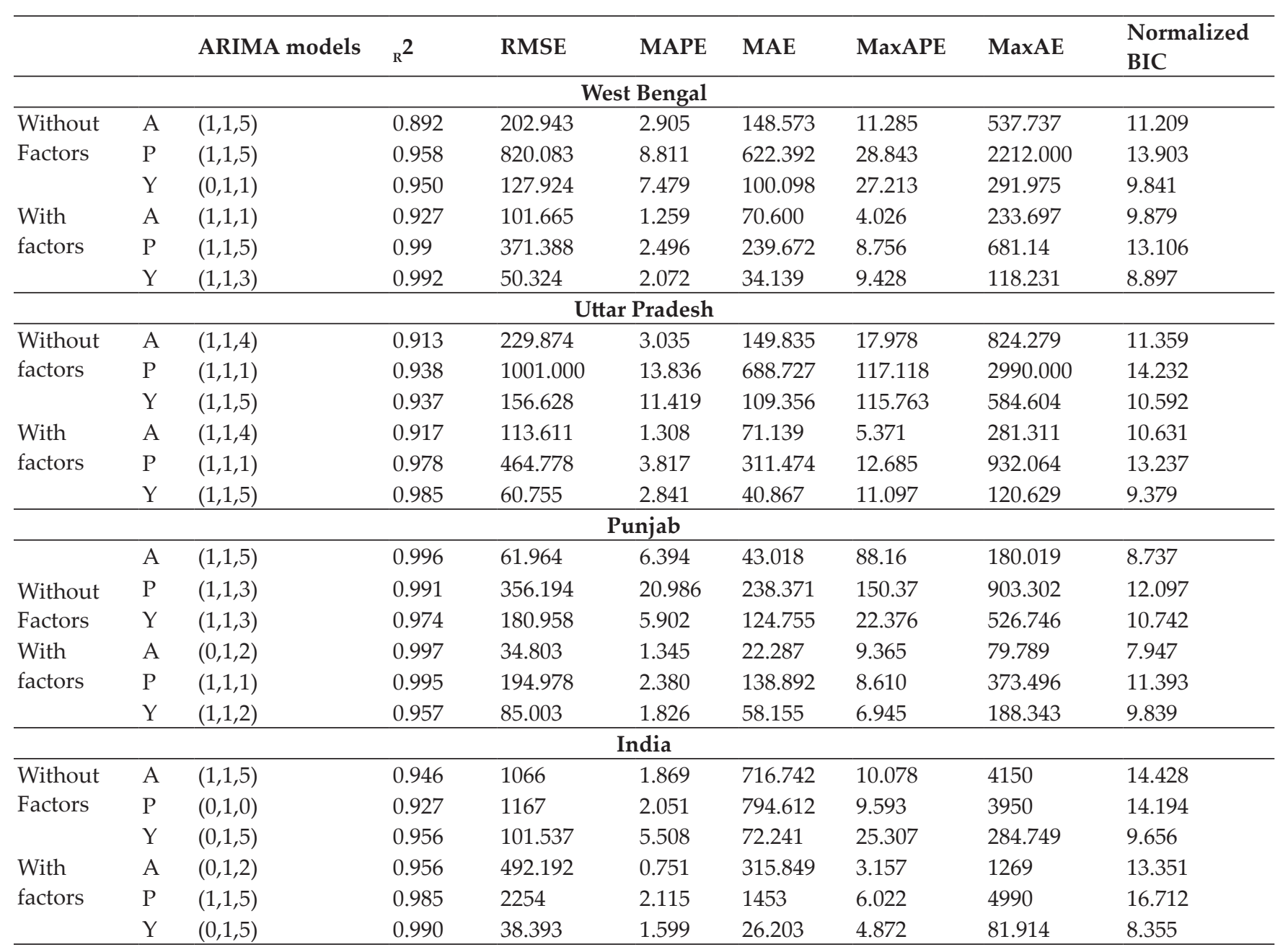


Table 5: Model validation and forecasting of area, production and yield of rice in India

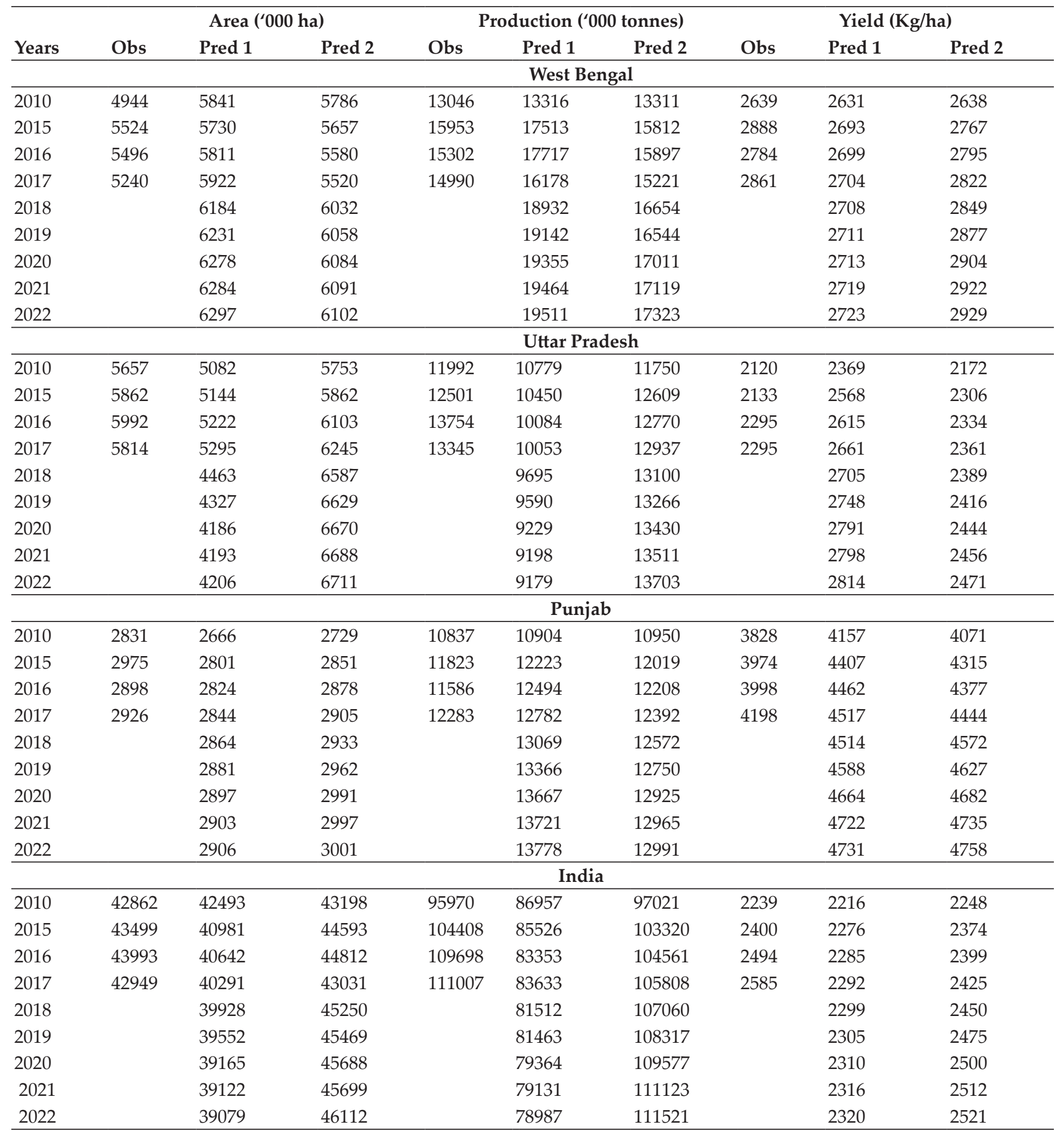

Obs.: Observed, Pred.1: Predicated values without factors (Simple ARIMA), Pred.2: Predicated values with factors (ARIMAX).

to produce 13.7 million tones of paddy from an estimated area of 3 million hectare at a yield rate of more than $4.7 \mathrm{q} / \mathrm{ha}$, All these estimate leads to a total 111 million tones of paddy from an estimated area of 45.7 million hectare at an average yield of 2.52q/ha during the same period.

\section{CONCLUSION}

From the present investigation, it is found that rainfall has changed randomly during the study period for West Bengal, Uttar Pradesh, and Punjab. ARIMA modeling has long historical background throughout the world. In the present study, 
forecasting models have been compared with and without including different factors of production. It is evident from the study the meteorological factor besides helping crop production, are also important in increasing efficiency and accuracy of the crop forecasting models. Non-stationary time series data on different production parameters could be made stationery after $I^{\text {st }}$ differencing and which show better accuracy in the ARIMA models after the inclusions of factors (ARIMAX) of productions; in the process forecasting power of selected models get enhanced. During the model validation period, a model with the factors i.e., the ARIMAX predicted closely to realized values, whereas during the out of sample forecasting, these have got tendencies to predicting lower values compared to other competitive models. For production, when we see the expected values, it is clear that West Bengal, Uttar Pradesh, and Punjab will have to play a vital role in the rice production of India. Punjab, in terms of the productivity of rice, would be the leading state of India. The study reveals that knowing the production potentials in association with factors of production will improve the forecasting accuracy, which in turn may help in formulating effective agriculture policy related to the particular crop.

\section{REFERENCES}

Anonymous. 2011. www.indiastat.com, Last accessed December 11.2011.

Anonymous. 2011. www.indiawaterportal.com, last accessed January 20.2011.

Anonymous. 2017. Agriculture at a Glance. Available from http://www.agricoop.nic.in/Last accessed on 20 Oct. 2017.

Anonymous. Various issue. Fertilizer statistics, Govt. of India.

Biswas, R., Banerjee, S. and Bhattacharyya, B. 2018. Impact of temperature increase on performance of kharif rice at Kalyani, West Bengal using WOFOST model. J. Agrometeorol., 20(1): 28-30.

Box, G.E.P. and Jenkins, G.M. 1976. Time Series Analysis: Forecasting and Control, Holden-Day, San Fransisco.

Diebold, F.X. and Mariano, R.S. 1995. Comparing predictive accuracy. J. Bus. Econ. Stat., 13: 253-263.

Ďurka Peter, Pastoreková Silvia. 2012.ARIMA vs. ARIMAX - which approach is better to analyze and forecast macroeconomic time series. Proceedings of $30^{\text {th }}$ International Conference Mathematical Methods in Economics.

Food and Agriculture Organisation of the United Nations 2002. Nutritional studies, F.A.O., Rome.
Gideon E. Schwarz. 1978. Estimating the dimension of a model, Ann. Stat., 6(2): 461-464.

Gouri K. Bhattacharyya. 1984. Tests of randomness against trend or serial correlations Handbook of Statistics, Elsevier, Volume 4, Pages 89-111, ISSN 0169-7161, ISBN 9780444868718, https://doi.org/10.1016/S01697161(84)04007-4.

Grubbs, F.E. 1950. Sample criteria for testing outlying observations. Ann. Math. Stat., 21: 27-58.

Grubbs, F.E. 1969. Procedures for detecting outlying observations in samples. Technometrics, 11(1): 1-21.

Grubbs, F.E. and Beck, G. 1972. Extension of sample sizes and percentage points for significance tests of outlying observations. Technometrics, 14: 847-854.

Harvey, D., Leybourne, S. and Newbold, P. 1997. Testing the equality of prediction mean squared errors. Int. J. Forecast., 13(2): 281-291.

Intriligator, M.D., Bodkin, R.G. and Hsio, C. 1996. Econometric Models, Techniques, and Applications", Prentice Hall edition.

Joshi, P.K., Gulati, A., Birthal, P.S. and Tewari, L. 2004. Agriculture diversification in South Asia: Patterns, determinants and policy implications. Econ. Polit. Wkly, 39(18): 2457-2467.

Joshi, P.K., Tewari, L. and Birthal, P.S. 2006. Diversification and its impact on smallholders: Evidence from a study on vegetable production. Agric. Econ. Res. Rev., 19(2): 219-236.

Kaul, S. 2006. Economic Analysis of Productivity of Rice Production-State-wise Analysis presented at the $14^{\text {th }}$ Annual Conference of Agricultural Economics Research Association, held during Sept. 27-28, 2006 at G.B. Pant Univ. of Agri. \& Tech.., Pant Nagar, Uttaranchal.

Kebebe, Ergano, Mehta, V.P. and Dixit, P.N. 2000. Diversification of agriculture in Haryana: An empirical analysis. Agril. Situation in India, 57(8): 459-463.

Khush, G. 2003. Productivity improvements in rice. Nutr. Rev., 61(6 Pt 2): S114-S116.

Mishra, P., Fatih, C., Niranjan, H.K., Tiwari, S., Devi, M. and Dubey, A. 2020. Modelling and Forecasting of Milk Production in Chhattisgarh and India. Indian J. Anim. Res., 54(7): 912-917.

Mishra, P., Sahu, P.K., Padmanaban, K., Vishwajith, K.P. and Dhekale, B.S. 2015. Study of Instability and Forecasting of Food Grain Production in India. Int. J. Agric. Sci., 7(3): 474-481.

Mishra, P., Sahu, P.K., Dhekale, B.S. and Vishwajith, K.P. 2015. Modeling and forecasting of wheat in India and their yield Sustainability. Soc. Eco. Dev., 11(3): 637-647.

Mishra, P., Matuka, A., Abotaleb, M.S.A., Weerasinghe, W.P.M.C.N, Karakaya, K. and Das, S.S. 2021. Modeling and Forecasting of Milk Production in the SAARC countries and China, Model. Earth Syst. Environ., pp. 1-9.

Mishra, P. 2015. Study of instability and forecasting of food grain production in India. Int. J. Agric. Sci., ISSN, 09753710. 


\section{P. Mishra et al.}

Raiger, H.L., Sahu, P.K., Behera, M.P. and Jajoriya, N.K. 2019. Variation and Character Association in Seed Yield and Related Traits in Rice Bean (Vigna umbellata). Int. J. Agric. Environ. Biotech., 12(1): 13-16.

Ramesh, T., Rathika, S., Subramanian, E. and Ravi, V. 2020. Effect of Drip Fertigation on the Productivity of Hybrid Rice. Int. J. Agric. Environ. Biotech., 13(2): 219-225.
Ravichandran, S., Muthuraman, P. and Rao, P.R. 2012. Time - series modelling and forecasting India's rice production - arima vs stm Modelling approaches. Int. J. Agric. Stat. Sci., 8(1): 305-311. 